\title{
ONICOMICOSE E VERRUGAS PLANTARES: DIAGNÓSTICOS E TRATAMENTOS
}

\author{
Tifany Meireles Mendes de Oliveira', Lorrane Corraide Santana Leis', \\ Débora Maria Rodrigues de Souza', Christianne Pimenta Dias'1, Nilza da Silva', \\ Marcela da Conceição de Castro', Christiana Vargas Ribeiro ${ }^{2,1}$
}

${ }^{1}$ Discente do Instituto Educacional São Camilo de Belo Horizonte, Minas Gerais, Brasil.

${ }^{2}$ Docente do Instituto Educacional São Camilo de Belo Horizonte, Minas Gerais, Brasil.

\section{RESUMO}

Onicomicose é uma infecção fúngica que se desenvolve nas unhas, sendo que as mais acometidas são as dos pés. Verrugas plantares também acometem a região palmoplantar, sendo causadas pelo Papilomavírus Humano (HPV), geralmente de tipo 1. A ação do podólogo é fundamental em ambas para estabelecer tratamento e principais cuidados, visando à adoção dessas medidas na rotina do paciente, para evitar que estas doenças afetem mais sua saúde e qualidade de vida. Para este estudo, foram realizadas pesquisas bibliográficas, de caráter qualitativo, em sites oficiais que abordam o tema estudado. Um dos estudos analisados aponta que, de 40 pacientes, $72,5 \%$ apresentaram o exame micológico direto (EMD) positivo enquanto em 17 pacientes, o resultado foi positivo para EMD e cultura. Isso mostra a importância de um diagnóstico correto juntamente à terapêutica estabelecida com o especialista, além do compromisso do paciente, como fatores fundamentais para o estabelecimento da cura perante estas patologias.

Palavras-chave: onicomicose, verrugas, HPV, diagnóstico, tratamento.

\section{INTRODUÇÃO}

As onicomicoses são infecções ungueais causadas por espécies fúngicas, incluindo as leveduras e os fungos filamentosos dermatófitos e não-dermatófitos. São consideradas superficiais, difíceis de diagnosticar e tratar. Nas lesões clássicas, há um descolamento irregular da borda livre da unha, associado ao espessamento da lâmina, hiperqueratose subungueal, máculas esbranquiçadas na superfície ungueal ou mesmo distrofia total (SOARES et al., 2020).

Existem quatro tipos de onicomicoses, que são classificadas de acordo com a sua apresentação clínica: a subungueal distal e lateral, em que a invasão começa no hiponíquio e na borda distal lateral da lâmina ungueal, estendendo-se de forma lenta e progressiva até o setor proximal da unha; a subungueal proximal, que é considerada a variante clínica menos comum, sendo observada com maior frequência em indivíduos com
Síndrome da Imunodeficiência Adquirida (AIDS), e inicia-se pela invasão do fungo no estrato córneo da dobra ungueal proximal e subsequentemente, na lâmina ungueal; a branca superficial, que é caracterizada pela penetração in situ de estruturas fúngicas em direção ao interior da lâmina ungueal, podendo ser facilitada por traumas anteriores; e a onicodistrofia, que é o estágio final das onicomicoses por dermatófitos ou Candida sp., onde verifica-se o acometimento da matriz ungueal, e a totalidade da unha encontrase alterada (FILHO et al., 2008).

O diagnóstico laboratorial das onicomicoses pode ser realizado pelo exame micológico direto (EMD), por cultura fúngica e exame histopatológico. O EMD é a primeira etapa do diagnóstico laboratorial indicando, na maioria das vezes, se o material examinado contém ou não estruturas fúngicas que são avaliadas quanto a morfologia e a coloração, auxiliando na conduta clínico laboratorial. A cultura é necessária para o isolamento e identificação da espécie, devendo o material ser inoculado sempre

AAutor correspondente: Christiana Vargas Ribeiro - E-mail: christianavargas@yahoo.com.br - Orcid: https://orcid.org/0000-0003-3213-6394

DOI: https://doi.org/10.36271/iajp.v3i1.57 - Artigo recebido em: 15 de novembro 2021; aceito em 17 de novembro de 2021 ; publicado em 22 de novembro de 2021 na Revista Ibero-Americana de Podologia, ISSN 2674-821. Disponível em http://journal.iajp.com.br - Todos os autores contribuíram igualmente ocartigo. Este é um artigo de acesso aberto sob a licença CC - BY: http://creativecommons.org/licenses/by/4.0. 
em diferentes meios. Já no exame histopatológico da lâmina ungueal, as hifas são vistas dispostas entre as camadas da unha paralelas a superfície (FILHO et al., 2008).

Após o diagnóstico, o tratamento convencional das onicomicoses é feito com a associação de medicamentos tópicos e sistêmicos. O tratamento tópico, embora menos eficaz, geralmente é preferido pelos pacientes. Os esmaltes antifúngicos tópicos foram formulados para proporcionar uma melhor distribuição do fármaco pela unha, com menos efeitos colaterais (LEAL et al., 2011).

O tratamento das onicomicoses pode requerer terapia de longo prazo, portanto, é importante diagnosticar corretamente a infecção, além de identificar o agente etiológico (FILHO et al., 2008). A persistência do paciente e alguns cuidados de higiene são fundamentais para o sucesso e a cura da patologia (LEAL et al., 2011).

Outra patologia que acomete a região palmoplantar é a verruga. Ela pode ser profunda, comumente dolorosa e causada pelo Papilomavírus Humano (HPV), geralmente do tipo 1. Quando se desenvolve mais superficialmente, formando placas hiperceratóticas, denomina-se verruga em mosaico, que é menos dolorosa e habitualmente causada pelo HPV tipo 2. Outro tipo de papilomavírus, que é detectado em lesões de verrugas plantares e são mais comuns na região palmoplantar é o do tipo 4 (LETO et al., 2011).

Tratando-se de um vírus contagioso, o HPV faz com que algumas células da pele se desenvolvam de forma mais rápida do que o habitual, causando infecções na pele e nas mucosas. A infecção ocorre pelo contato direto ou indireto com o indivíduo que tem a lesão. Disfunções na barreira epitelial por traumatismos, pequenas agressões ou macerações provocam perda de solução de continuidade na pele, possibilitando a infecção viral. Após a inoculação, o período de incubação varia de três semanas a oito meses (LETO et al., 2011).

O diagnóstico das verrugas é realizado através de biopsia da pele, de punção ou de uma biopsia cutânea incisional. O exame físico é realizado por um médico ou podólogo, e compreende a avaliação da lesão cutânea, com o intuito de detectar pequenos vasos sanguíneos coagulados ou pontos escuros; e nos casos mais graves, recomenda-se a biopsia, que é a retirada de uma amostra da verruga para ser analisada em laboratório (CHÁVEZ e PÉREZ, 2020).

Existem múltiplos tratamentos (ceratolíticos, crioterapia, eletrocoagulação, dentre outros) para estas verrugas, mas não garantem a cicatrização das lesões. A bleomicina é uma opção terapêutica em casos rebeldes e recalcitrantes; tem atividade antibiótica, antibacteriana, antiviral e citotóxica (antineoplásica) (CIVALE et al., 2019).

\section{OBJETIVOS}

\section{Objetivo Geral}

Determinar a ação do podólogo no tratamento e no diagnóstico de onicomicoses e verrugas plantares.

\section{Objetivos Específicos}

Estabelecer a conduta podológica adequada no tratamento de pacientes com suspeita de onicomicose e verrugas plantares;

Estabelecer os principais cuidados, visando à adoção dessas medidas na rotina do paciente, para evitar que estas doenças afetem sua saúde e qualidade de vida.

\section{METODOLOGIA}

O estudo consiste em uma pesquisa bibliográfica, de caráter qualitativo, através do uso de bases de dados como, a Literatura Latino-Americana e do Caribe em Ciências da Saúde (LILACS), Scientific Eletronic Library Online (SciELO) e o Google Acadêmico, além do site da Sociedade Brasileira de Dermatologia (SBD). A pesquisa contempla artigos científicos em língua portuguesa, inglesa e espanhola a partir do ano de 2007 a 2021. Os indicadores utilizados para a construção do trabalho foram: micose, onicomicose, verrugas, verrugas plantares, papilomavírus e resultado, totalizando 8 artigos. Os critérios de inclusão foram: artigos e sites oficiais que abordassem o tema estudado e contivessem as patologias onicomicose e verrugas plantares. Os critérios de exclusão foram: artigos que não abordassem as patologias pesquisadas.

\section{RESULTADOS E DISCUSSÃO}

Filho et al. (2008) selecionaram 40 pacientes com suspeita clínica de onicomicose e os avaliaram através de três métodos diagnósticos (exame micológico direto - EMD, biopsia e cultura). Notou-se que o EMD foi o que classificou maior quantidade de pacientes com onicomicose, $72,5 \%$. Em contrapartida, o exame histopatológico classificou apenas $35 \%$ dos pacientes com esta patologia. Dos 40 pacientes analisados, observou-se que nove tiveram resultado positivo nos três métodos diagnósticos, e em 17 pacientes, o resultado foi positivo em dois métodos (EMD e cultura). Quanto à biopsia, não se mostrou sensível e apresentou especificidade equivalente à dos outros exames, chegando a esse resultado após análises laboratoriais. De acordo com o estudo, foi constatado que os exames apenas confirmam a presença de fungos, porém não informam a espécie do patógeno. Sendo assim, a grande maioria dos pacientes acaba sendo tratada com diversos tipos de terapias, somente com a suspeita de onicomicose, sem comprovação diagnóstica. Novos estudos têm desenvolvido métodos de coleta detalhada, como a curetagem com cortador de unha e/ou bisturi de n.15, sendo interessantes para obter amostras maiores e uma possível melhora nos resultados.

Considerando os dados epidemiológicos e micológicos de um estudo em que foram analisados 200 fragmentos de unhas de 184 pacientes, com o objetivo de investigar a incidência das onicomicoses, através da raspagem subungueal ou superficial da unha divididos em exame direto e cultura, observou-se que $80 \%$ 
dos pacientes eram mulheres. A faixa etária mais acometida foi entre 36 e 64 anos, representando $62 \%$ dos pacientes estudados; $19 \%$ tinham idade entre 19 e 35 anos, enquanto $17,4 \%$ eram idosos acima de 65 anos, demonstrando ser uma doença de prevalência em adultos. A maior parte dos pacientes, como adultos $(62 \%)$ e mulheres $(80 \%)$ tinham profissões que, porventura, utilizavam instrumentos de trabalho contaminados, sofriam traumas no exercício das atividades domésticas e exposição à produtos químicos, que são considerados fatores de risco para a onicomicose. Das amostras recolhidas, a levedura Candida albicans e o fungo filamentoso Trichophyton rubrum foram os mais comuns. Notou-se uma sensibilidade aos fármacos cetoconazol e anfotericina B, comprovando-se que a profilaxia , associada a não realização do tratamento terapêutico por parte dos pacientes, justificou as falhas encontradas na ausência de cura (ALMEIDA et al., 2007).

Aida (2014) investigou a incidência de verrugas plantares em 50 pacientes. A resposta de $86 \%$ dos podólogos que colaboraram com o estudo, mostra que a verruga plantar comum é o tipo que tratam com maior frequência nas consultas podológicas, seguida de $8 \%$ pela verruga exofílica plantar, com $4 \%$ pela verruga mosaico, e $2 \%$ pela verruga plana. Em relação à localização da verruga, $76 \%$ das respostas afirmam que a região metatarsal é a área com maior aparecimento, $20 \%$ correspondem à região talar, $4 \%$ à área digital. Com relação ao tratamento, $60 \%$ dos resultados afirmam que os podólogos levam em consideração a localização da verruga na escolha terapêutica, enquanto $40 \%$ não levam em consideração esta informação. Assim como $66 \%$ dos resultados afirmam que levam em consideração a idade do paciente como forma de exclusão na escolha de um tratamento, 34\% não o fazem. Em outra análise, $78 \%$ dos podólogos pesquisados levam em consideração as doenças que o paciente apresenta ao escolher um tratamento, enquanto $22 \%$ não. Com base nos $76 \%$ das respostas, pode-se afirmar que o tipo de tratamento mais utilizado pelos podólogos corresponde aos tratamentos químicos, seguido de $10 \%$ dos tratamentos físicos, com $8 \%$ de tratamentos homeopáticos, $4 \%$ de tratamentos medicamentosos, e $2 \%$ de tratamentos cirúrgicos. Em $42 \%$ das respostas, é possível concluir que o tempo médio de cicatrização de uma verruga tratada corresponderia a mais de 1 mês, $40 \%$ indicam que corresponderia a um tempo médio de 1 mês, $10 \%$ a uma semana e $8 \%$ a duas semanas.

Já em outro estudo, onde mostram a eficácia da pomada de ureia em pacientes com verrugas plantares, dos 60 pacientes investigados, $66,7 \%$ eram do gênero masculino e $33,3 \%$ do feminino. A faixa etária predominante foi de 25 a 34 anos (45\%). Em $45 \%$ dos integrantes, as verrugas plantares localizavam-se no pé direito, em $31,7 \%$ no esquerdo e em $23,3 \%$ em ambos os pés. As lesões predominantes em ambos os grupos de tratamento foram de 2 a $4 \mathrm{~mm}$ de diâmetro (60\%), seguidas de 5 a $7 \mathrm{~mm}(16 \%)$, de forma que coincidiram com aquelas que apareceram em mosaico. Vinte e um dos pacientes do estudo (70\%) foram curados com 1 a 3 lesões, assim como $20(66,7 \%)$ dos considerados controles. Para que um esquema terapêutico se torne totalmente eficaz, uma resposta imunológica adequada no hospedeiro é essencial, embora os melhores resultados sejam obtidos em indivíduos mais jovens e com menor duração da infecção pelo HPV. Ocasionalmente, porém, as lesões reaparecem após a realização do tratamento, devido à persistência dos queratinócitos infectados (Lescay et al., 2009).

\section{CONSIDERAÇÕES FINAIS}

De acordo com as pesquisas realizadas observou-se que, a onicomicose pode ser diagnosticada através de exame micológico direto, cultura fúngica e exame histopatológico. A partir de um diagnóstico correto e de uma anamnese adequada, o tratamento é iniciado. Medicamentos tópicos e/ou orais, além das consultas preventivas ao podólogo são fundamentais para o sucesso do tratamento que, habitualmente, é longo e necessita da adesão e conscientização dos pacientes. Em relação às verrugas plantares, verificou-se que é uma patologia comum em pessoas portadoras de HPV (Papilomavírus Humano), um vírus contagioso que causa infecções cutâneas; e possui 3 formas diagnósticas (biopsia da pele, punção e biopsia cutânea incisional). Após o diagnóstico, o podólogo irá avaliar o melhor tratamento a ser estabelecido para o paciente. Quanto mais rápido o diagnóstico, mais rápida será estabelecida a conduta terapêutica e maiores serão as chances de cura dos pacientes.

\section{REFERÊNCIAS}

FILHO, et al. Avaliação dos métodos diagnósticos para onicomicose. Anais Brasileiros de Dermatologia [online]. 2008, v. 83, n. 2 [Acessado 25 Outubro 2021],pp.119-124. Epub-2008-Disponível em: https://www.scielo.br/j/abd/a/ TQ98gwWcWzNfnm6yhBGjXvp/?lang=pt

SOARES, GABRIELA MANEA et al. Onicomicose simulando melanoma acral ungueal: relato de caso. Publicação: 2020. [Acessado 25 Outubro 2021] Portal Regional da BVS - 2020 Disponível em https://pesquisa.bvsalud.org/portal/resource/pt/ biblio-1116019

LETO, et al. Infecção pelo papilomavírus humano: etiopatogenia, biologia molecular e manifestações clínicas - An Bras Dermatol. 2011;86(2):306-17. [Acessado 25 Outubro 2021] - Disponível em: https://www.scielo.br/j/abd/a/ W8xQS6MSSk7tT8CLRCnbs8f/abstract/?lang=pt

CHÁVEZ, PÉREZ. Epithelioma cuniculatum associado ao vírus do papiloma humano. Apresentação do caso. Rev haban cienc medic vol.19 no.3 Havana mai.jun. 2020 Epub 10-Jul-2020: http://scielo.sld.cu/scielo.php?script=sci_ arttext\&pid=S1729519X2020000300005\&lang=pt

CIVALE, etal. Tratamento de verrugas plantares combleomicina: relato de caso. Rev. argent. dermatol. vol.100 no.3 Conjunto da Cidade Autônoma de Buenos Aires. 2019 Epub 30-Set-2019. http://www.scielo.org.ar/scielo.php?script=sci_arttext\&pid=S1851300X2019000300106\&lng=es\&nrm=iso\&tIng=es

GALLEGO, Aida.: <file:///C:/Users/Usuario/Downloads/59453. 
es.pt.pdf > publicado em 12 de Junho de 2014 - Estudo comparativo do tratamento de verrugas plantares por podólogos da Área Metropolitana de Barcelona e estudos publicados - universitat Barcelona

LEAL et al., 2011. Uso de ondas de alta frequência no tratamento de onicomicose: comunicação preliminar de três casos. [Acessado em 04 novembro 2021] disponível em https:// www.scielo.br/j/abd/a/dgZBX5YXFgz7D83jTCDsndJ/?lang=pt\#

LESCAY, CELSO et al. Efectividad de la pomada de urea en las verrugas plantares. MEDISAN, Santiago de Cuba, v. 13, n. 5, oct. 2009 . >. 2021 http://scielo.sld.cu/scielo.php?script=sci arttext\&pid=S102930192009000500003\&lng=es\&nrm=iso. 